\title{
Implementation and Practical Benefits of ISO/IEC 17025:2005 in a Testing Laboratory
}

\author{
F Khodabocus * \\ Faculty of Engineering, \\ University of Mauritius \\ Reduit \\ Email: f.khodabocus@uom.ac.mu \\ K Balgobin \\ Email: kooshal_b@hotmail.com
}

Paper Accepted on 06 January 2011

\begin{abstract}
The Paper presents a study of laboratory accreditation in a testing laboratory, the implementation steps and the practical benefits derived from such an enterprise. ISO/IEC 17025:2005 - General Requirements for the Competence of Testing and Calibration Laboratories is the standard used for laboratory accreditation. An evaluation and comparison of the quality system in a case study laboratory, XYZ Laboratory, to the quality management system of an accredited laboratory showed that some of the requirements of the standard were being met to some extent while some clauses required the development of appropriate procedures before implementation could occur. The precision of the laboratory results was also investigated and found to reach acceptable levels. The impacts and benefits of accreditation were analysed. It was found out that though workload increases along with running costs with laboratory accreditation, the multiple advantages like marketing advantage and international recognition outweigh the difficulties encountered while setting up the system. The feasibility of accreditation showed that laboratory accreditation is a demanding process and it requires significant investment, in the preliminary stages. The cost issue will require the financial support of top management.
\end{abstract}


An implementation guideline for ISO/IEC 17025:2005, addressing all the requirements of the standard has been developed for this study. It can be used as a guide to implement a quality management system in a testing laboratory. Results, discussions and recommendations have led to the conclusion that laboratory accreditation is a challenging process. The success of the implementation of a quality management system, based on ISO/IEC 17025:2005, is achievable if there is commitment from top management and through adequate staff involvement.

*For correspondences and reprints

\section{INTRODUCTION}

Nowadays, a wide range of socio-economic activities depend on measurements. Food safety, health and environmental protection are dependent on chemical analyses. As we rely heavily on them, our confidence in chemical measurements can only be boosted by their accuracy. Laboratory accreditation, achieved through the implementation of the ISO/IEC 17025:2005 standard is the process which determines the competence of laboratories in delivering accurate results. On the global scale, with the economic crisis, manufacturers and suppliers need to reduce their operating costs. Using accurate and reliable data, emanating from internationally recognised accredited laboratories, eliminates the need for retesting, thus, reducing costs and minimising technical barriers to trade.

In Mauritius, the use of quality management systems and laboratory accreditation are acquiring significance in various sectors. Companies are now aware of the benefits of implementing quality management systems and acquiring accreditation. Though the implementation and maintenance processes involve major investment, organisations are conscious of the fact that customer satisfaction is an important asset to their business. Moreover, government bodies are more likely to seek the services of an accredited laboratory knowing that their decisions will be based on accurate and reliable data. 
With the objective of becoming a commercial hub for the southern African region, Mauritius should encourage its laboratories to go for accreditation. The Ministry of Industry, Science and Research already possesses a department, MAURITAS, which acts as the national accreditation body. With the signature of mutual recognition arrangements (MRAs), accredited Mauritian laboratories will benefit from international recognition of their results. International recognition will, undoubtedly, represent an advantage for accredited laboratories.

\section{AIMS AND OBJECTIVES OF THE STUDY}

The aims of the project are to design an approach for the implementation of a quality management system in compliance with the requirements of ISO/IEC 17025:2005 at XYZ laboratory and to enumerate the practical benefits derived from laboratory accreditation.

The aims will be achieved through the following objectives:

1) Analysis of the clauses of the ISO/IEC 17025:2005 standard which would be applicable to the quality management system (QMS) of XYZ laboratory.

2) Evaluation of the existing quality system at XYZ compared to a QMS of an already accredited laboratory.

3) Discuss the benefits of accreditation and assessing the feasibility of the accreditation process.

4) Develop an implementation guideline for the XYZ laboratory.

\subsection{Scope of Study}

This study involves the identification and assessment of the various aspects to be considered for the implementation of a QMS based on the ISO/IEC 17025:2005 standard at XYZ laboratory. As ISO 9001:2000 requirements are part of the ISO/IEC 17025:2005 standard, the scope of the project can also be defined as an integration of both these standards. 


\subsection{Limitations of Study}

Due to the numerous issues involved in this endeavour and the short time interval, consideration will be given to the general features for operation of a quality management system in the laboratory. Emphasis will be laid on the approach to be adopted in order to achieve the requirements of the ISO/IEC 17025:2005 standard and the practical benefits linked to the implementation of such a system.

\section{INTRODUCTION TO QUALITY}

It is an undeniable fact that, in our contemporary world, being competitive is the key to success for any company. Competitiveness involves delighting the customer and exceeding his expectations and to achieve these goals, there is a need for quality. The benefit attached to the quality of products is the reputation it brings to the company. In addition, the search for quality drives companies towards continual improvement of their management system and development of efficient ways to meet customer satisfaction. Moreover, the impact of quality on cost should not be neglected and this is explained by Deming's philosophy (Deming 2009) which says that as quality increases costs tend to fall over time as shown in Figure 1.

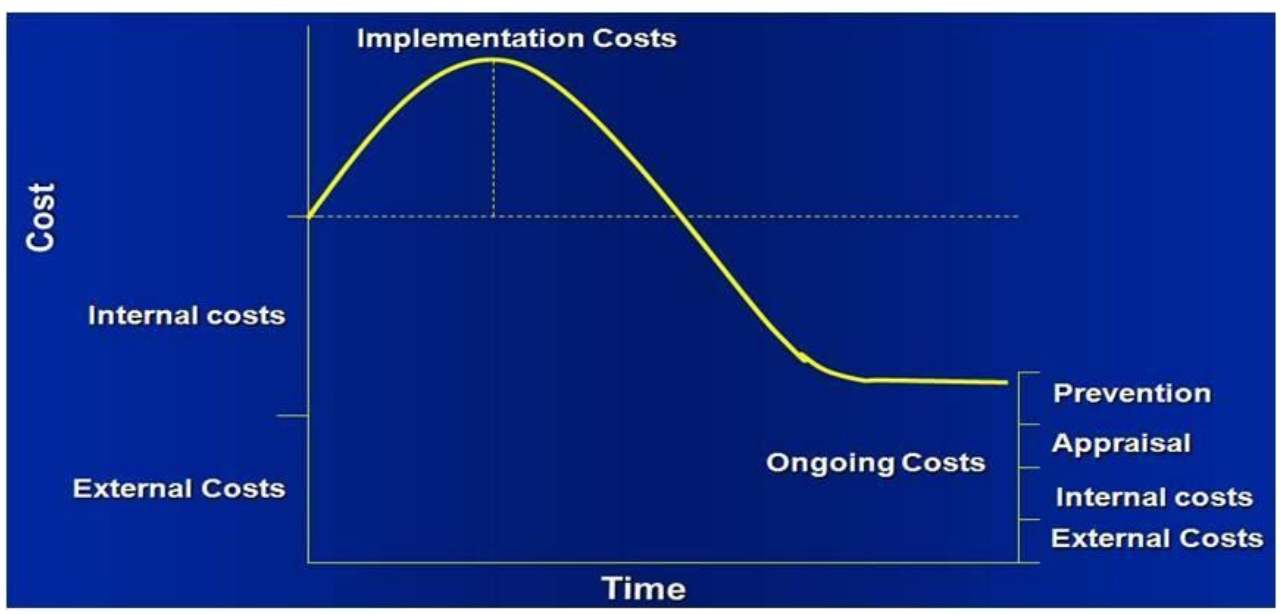

Figure 1: Effect of Quality Management on Costs

Source: Quality Management System for Laboratories 


\subsection{Quality in Mauritius}

The second half of the 1990's has seen the rapid implementation of quality standards in Mauritius. In 1994, ISO 9001 standard was revised by ISO and published. Since then, revised versions have been published and the last one is ISO 9001:2008. In Mauritius, the number of companies having implemented ISO 9001:2000 amounts to 259 (The ISO Survey 2007, p.14). There are three certification bodies that are currently involved in the process of certification to ISO 9001:2008 (Quality Management Systems), ISO 14001:2004 (Environmental Management Systems), ISO 22000:2005 (Food Safety Management Systems) and other quality management systems. These three certification bodies are:

1) Mauritius Standards Bureau (MSB).

2) Société Générale de Surveillance Ltée (SGS) Mauritius.

3) Anglo Japanese American / Environment Quality Systems (AJA / EQS).

In October 2008, 49 companies were registered to MSB for certification to ISO 9001:2008 (MSB National Quality Management System Certification Scheme 2008).

Accreditation of testing or calibration laboratories, through the implementation of the ISO/IEC 17025 standard, is also acquiring steady acceptance in local companies. The Mauritius Accreditation Service (MAURITAS) is the organisation responsible for assessing the compliance to the ISO/IEC 17025:2005 standard and delivering accreditation. Currently, there are eight testing laboratories which are accredited by the body (MAURITAS 2008).

\subsection{The Purpose of a QMS in a Testing Laboratory}

A QMS in a testing laboratory is a way of showing that the quality of the final test results can be relied upon. The presence of quality assurance, through the use of appropriate procedures and management methods, guarantees clients that errors, in test results, are minimised. The QMS provides the laboratory with measurement 
traceability, the opportunity of error prevention by the use of preventive actions and the possibility of initiating corrective action when errors are detected.

\subsection{Laboratory Accreditation}

ISO 9001 is the general standard which specifies the requirements for a quality management system, whereas ISO/IEC 17025 states the requirements for the competence of testing and calibration laboratories. Clients look for laboratories which can supply them with accurate and reliable results and the ISO 9001 standard does not cater for the technical competence of a laboratory. On the other hand, a laboratory accredited to the ISO/IEC 17025 standard has been evaluated for compliance to specific factors relevant to the laboratory's ability to deliver precise and accurate data. Some of these factors are:

1) Technical competence of staff

2) Validity of methods

3) Calibration and maintenance of equipment

4) Traceability of measurements

5) Estimation of measurement uncertainty

6) Quality assurance of test or calibration results.

The other quality system elements of ISO 9001 are also covered in ISO/IEC 17025. Therefore if a laboratory is concerned with demonstrating its technical competence, ISO/IEC 17025 is the appropriate standard (ILAC Laboratory Accreditation or ISO 9001 Certification, 2001). It is to be pointed out here that January 2009 IAF-ILAC-ISO issued a joint Communiqué on the Management Systems requirements of ISO/IEC 17025:2005, General requirements for the competence of testing and calibration laboratories. The communiqué was produced to clear the confusion caused by the perception that accredited laboratories do not operate a recognized quality management system. 


\subsubsection{Requirements of ISO/IEC 17025:2005}

Figure 2 denotes the general requirements which a laboratory has to abide by to demonstrate its competence in the fields of testing and calibration. ISO/IEC 17025:2005 is a revision of the previous standard known as ISO/IEC 17025:1999 which itself was based on ISO Guide 25. The latest version of the standard was released to display the compatibility between ISO/IEC 17025:2005 and ISO 9001:2000. With this change, ISO 9001:2000 can be seen as the master standard while ISO/IEC 17025:2005, the specific application of the standard to testing and calibration laboratories (Rowley 2005).

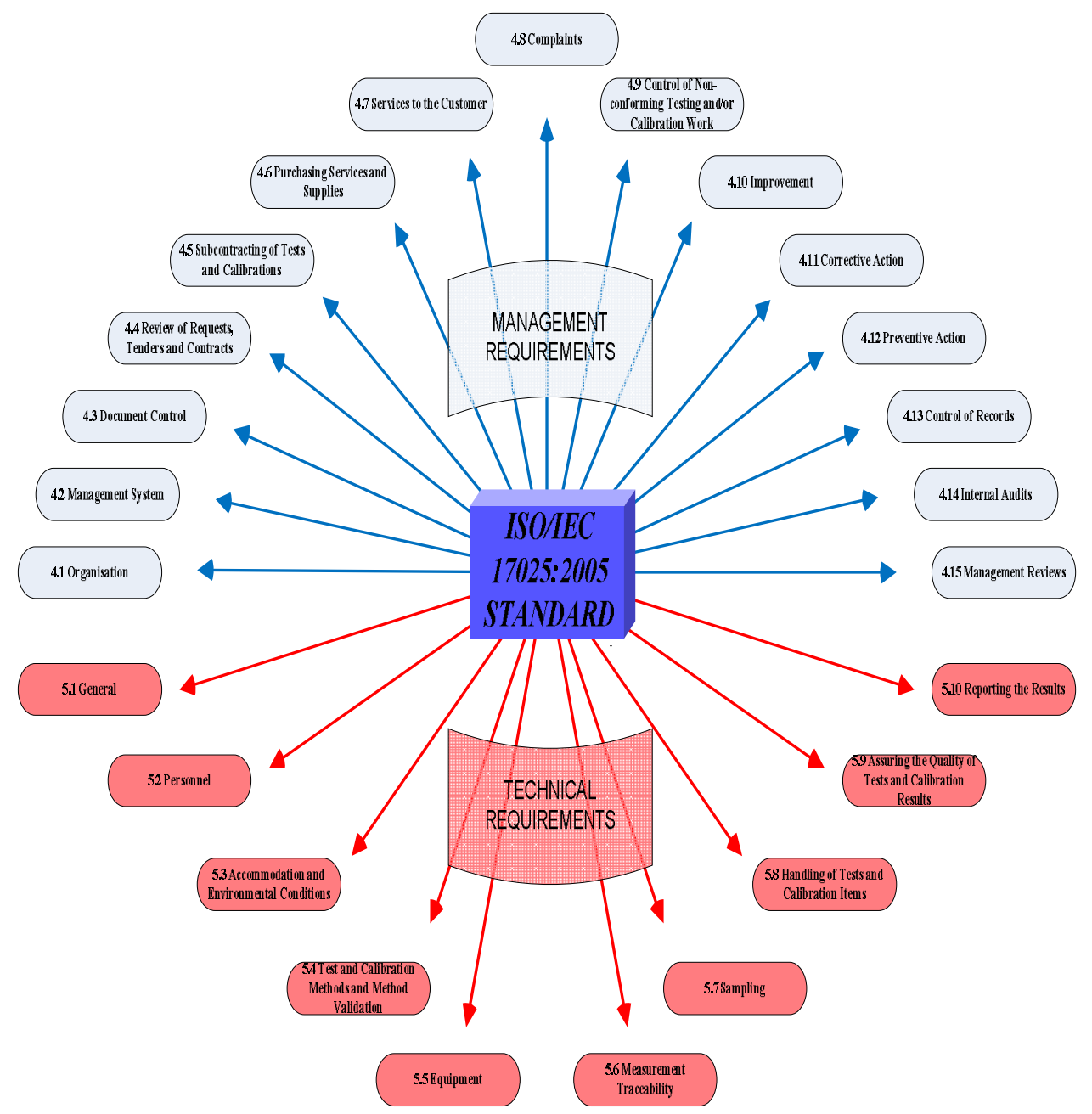

Figure 2: Management and Technical Requirements of ISO/IEC 17025:2005 


\subsubsection{The Accreditation Process}

For a testing laboratory, accreditation is the formal recognition that the laboratory possesses the necessary competence to carry out specific tests (Eurachem Guide to Quality in Analytical Chemistry 2002). As it is delivered by an independent, national or international body, accreditation assures the client of the validity of the test results. On a national scale, government bodies and regulators often need accurate information to take their decisions. Therefore, the benefits they derive from using data from an accredited laboratory are as follows:

1) Increase in public confidence.

2) Assurance that quality data is being used to establish baselines for key analyses and decisions.

3) Reduced uncertainties associated with decisions that affect the protection of human health and the environment.

4) Improved efficiency of assessment process.

Accreditation of laboratories plays an essential role on the international stage as it minimises barriers to trade. With accreditation, test results produced in one country is accepted in another country. The data generated by accredited laboratories is more readily acceptable on the overseas market. By reducing or eliminating the need for retesting in the importing country, manufacturers and exporters can reduce costs (ILAC Why Use an Accredited Laboratory, 2001). In order to obtain accreditation, a laboratory must be assessed by a third party independent body. The assessing body must itself conform to ISO/IEC 17011:2004, which specifies the general requirements for accreditation bodies accrediting conformity assessment bodies. Accreditation can be assessed by either national bodies or international ones. On an international level ILAC is the organization responsible for assessing National Accreditation bodies and MAURITAS is an associate member of ILAC. Moreover, if a laboratory wants to receive an accreditation which is recognized internationally, it can apply to any National Accreditation body which has been accepted as a signatory to the ILAC Mutual Recognition Arrangement (ILAC MRA) such as:

1) Singapore Accreditation Council (SAC) 
2) South African National Accreditation System (SANAS)

3) United Kingdom Accreditation Service (UKAS)

For a laboratory, operating a QMS based on ISO/IEC 17025:2005, wishing to achieve an accredited status, the first step is to contact the accreditation body. In the local context, the laboratory should apply to MAURITAS. The laboratory will send its manual for review. If the manual does not require any modification, MAURITAS will contact the laboratory in order to conduct an on site assessment. Qualified assessors will assess the QMS and operations of the applicant body. Technical assessment will involve spending time with the staff to check their technical knowledge, observe calibrations, and check whether test procedures are respected. The final product of the assessment is a detailed report highlighting nonconformities. The appropriate corrective actions need to be implemented before accreditation is delivered. It is to be pointed out that the accreditation granted is for specific tests and that the MAURITAS Accreditation Logo can only be used for test reports containing test results of the methods included in the Accreditation Scope.

\section{METHODOLOGY}

In order to achieve the aims and objectives of the project, several steps have been employed. The main stages of the study are as shown in Figure 3 below. 




Figure 3: Steps in the Methodology for the Study

\section{RESULTS}

From the results of the evaluation, it can be deduced that the laboratory operates a quality system but does not possess the appropriate documentation to implement it fully. With the development of the missing procedures and their implementation, the laboratory can operate an appropriate QMS conforming to the requirements of the ISO/IEC 17025:2005 standard.

\subsection{Comparison between Existing Quality System, in the Laboratory, to the Quality System in an Accredited Laboratory}

A questionnaire adapted from Rowley Associates (2005) on ISO 17025 was used for the comparison of the two systems. Each question was assigned a score ranging from one to four. The questionnaire was divided in subsections. Each subsection addresses the clauses of the standard as shown in Figure 2. A score of one meant that 
the requirement was not met at all, a score of two showed that some parts of the requirements are met, a score of three indicated that most parts of the requirements are met and the highest score, four, was assigned when all requirements were met. The results of the comparison between the two quality systems are given in Figure 4. Results indicate that although the laboratory does not operate a QMS, as in an accredited laboratory, it does abide to most of the clauses to some extent. Some of the requirements of the standard are nearly met by XYZ laboratory.

Customer service, complaints handling, control of data and integrity, handling of test and calibration items and reporting of results will require minimum adjustment to comply fully with the requirements of the ISO/IEC 17025:2005 standard.

Some clauses have received very few marks because they are only applicable when an appropriate quality management system is being run in the laboratory. The low score for internal audits and management review is explained by the fact that such activities are not planned due to the absence of a proper QMS. The gaps, existing in the other clauses, show that XYZ laboratory has to develop and implement appropriate procedures in order to reach an acceptable level of compliance to the ISO/IEC 17025:2005 standard. 


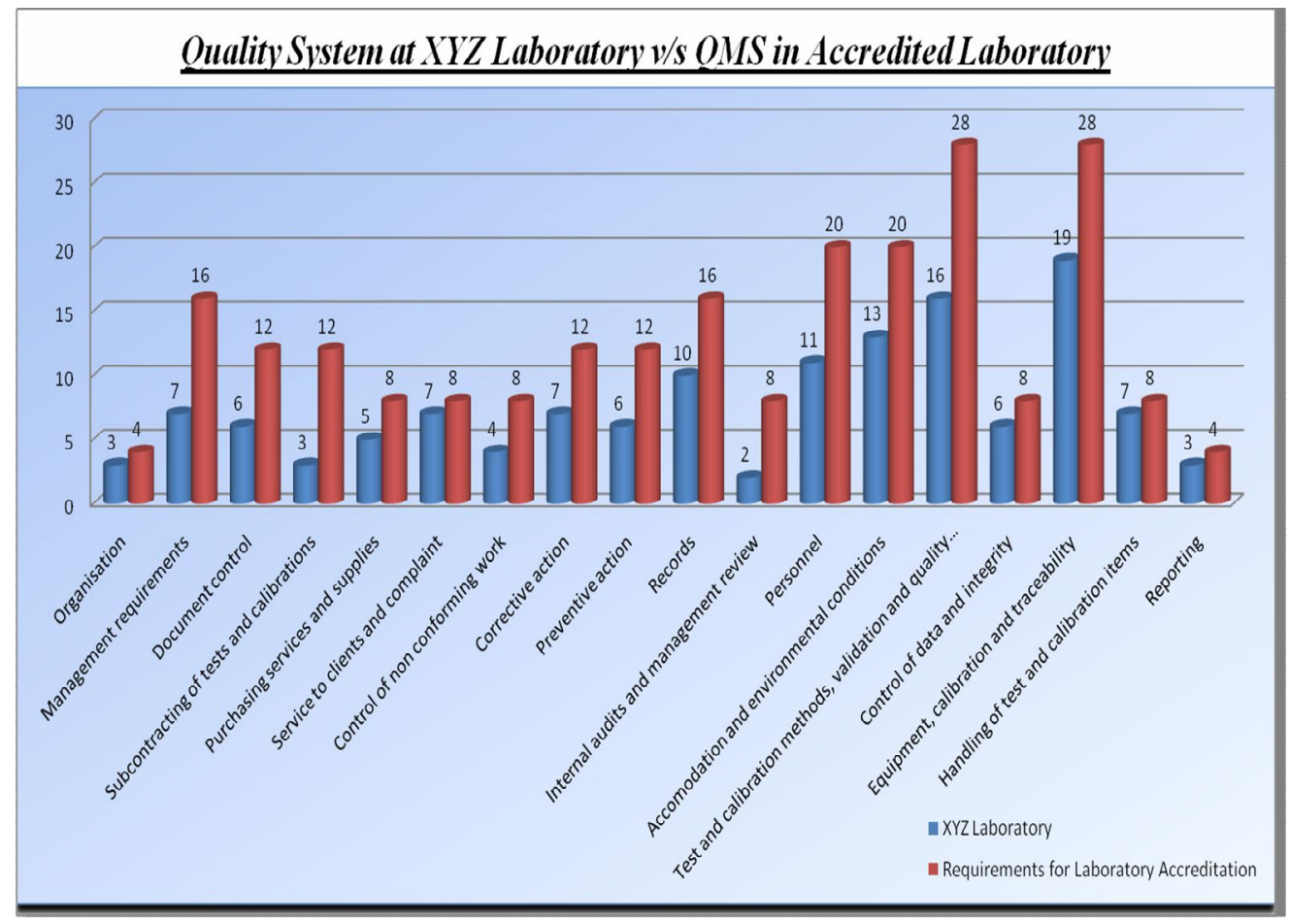

Figure 4: Results of Comparison between Quality System at XYZ Laboratory and QMS in an accredited laboratory

\subsection{Precision of Results Generated by XYZ Laboratory}

Results obtained from the tests carried out on the samples at XYZ laboratory are given below. From Table 1 it can be deduced, from the values of the standard deviations, that most of the test results obtained for the different parameters have a small standard deviation. It can also be seen that most of the values obtained are within one standard deviation of the mean value and within the permissible limits of the test methods. This observation, also, confirms that the test results are precise. As the standard deviation may be used as a measure of uncertainty, better results would have been obtained with at least 10 replicates using the method indicated in Table 1. (EURACHEM, 1998). The Fitness for Purpose of Analytical Methods). All results are expressed in $\mathrm{mg} / \mathrm{l}$. 


\begin{tabular}{|l|l|l|l|l|l|l|l|l|}
\hline \multicolumn{2}{|c|}{ SAMPLE 1 } \\
\hline & Test Method & Test 1 & Test 2 & Test 3 & Test 4 & Mean- & Variance - & $\begin{array}{l}\text { Standard } \\
\text { Deviation }\end{array}$ \\
& & $m g / l$ & $m g / l$ & $m g / l$ & $m g / l$ & $m g / l$ & $(m g / l)^{2}$ & $(m g / l)$ \\
\hline $\begin{array}{l}\text { Ammoni } \\
\text { a }\end{array}$ & APHA 4500 & 0.8 & 0.8 & 1.0 & 0.9 & 0.875 & $9.16 \times 10^{-3}$ & 0.0957 \\
\hline $\begin{array}{l}\text { Nitrate } \\
\text { as N }\end{array}$ & APHA 4500 & 10 & 8 & 10 & 7 & 8.75 & 2.25 & 1.5 \\
\hline Sodium & NOPHA 3500 & 173 & 169 & 175 & 178 & 174 & 14.2 & \\
\hline
\end{tabular}

Table 1: Results obtained from the tests carried out on the samples.

\section{Corresponding pH}

\begin{tabular}{|l|l|l|l|l|l|l|l|l|}
\hline $\mathrm{pH}$ & & 6.6 & 6.8 & 6.4 & 6.7 & 6.63 & 0.0292 & 0.171 \\
\hline
\end{tabular}

The value of the variance, for each set of values, is another measure of statistical dispersion. The variance gives the degree to which the values are spread out. From the calculated values for variance, it is observed that the spread is minimal and this observation provides evidence of the precision of the results. Having analysed the standard deviation and the variance, it can be deduced that the results, generated by XYZ laboratory, are adequately precise.

\section{DISCUSSION}

\subsection{Impacts and Benefits of Accreditation}

Accreditation will generally change the way a laboratory functions. The status acquired by a laboratory, the way the work is carried out and the additional 
paperwork represents some of the changes that will occur. The implementation of a QMS based on ISO/IEC 17025:2005 will modify the actual system prevailing in a laboratory and will also introduce new procedures. These alterations will generally have an effect on the laboratory, its personnel and the clients. Accreditation will increase paperwork and work load, internal quality control and running costs of operating the laboratory. There will be a need to maintain documentation procedures and records to operate the QMS, and the additional control of records to verify on tests carried out and calibration results. The validation for test methods is another additional load for laboratory staff. Calibration of equipment requires the use of calibration standards and reference materials and these add up to the running costs of the laboratory. For example $\mathrm{pH}$ meters need to be calibrated with buffer solutions and conductivity meters are calibrated with standard solutions. Internal Quality control can be implemented in many ways. It takes a variety of forms including the use of: blanks; measurement standards; spiked samples; blind samples; replicate analysis and QC samples (EURACHEM - Guide to Analytical Chemistry).

The benefits associated to accreditation can be analysed from three different angles; the laboratory's personnel, the laboratory itself and the clients. With the use of appropriate procedures, staff will be more confident about their work. They can easily identify errors and their sources. Thus they can implement necessary corrective actions. Accreditation demonstrates the technical ability of a laboratory to carry out specific tests and thus provides a formal identification to competent laboratories. This recognition is a way for the customer to select reliable testing services suited to his needs. The logo of the accreditation body on the test reports of the accredited laboratory ensures the client about the results delivered. (ILAC 2001).

Most accreditation bodies, around the world, have adopted ISO/IEC 17025:2005 as the basis for accrediting testing laboratories. As the approach is uniform, laboratory competence can be compared. Based on this approach, mutual recognition arrangements (MRAs) are established between countries and these allow the test and calibration data generated in one country to be accepted in the other country. These 
arrangements allow laboratories to achieve some form of international recognition as the results they will send abroad will be accepted as reliable and accurate.

\subsection{Feasibility of Accreditation and Associated Costs}

Accreditation of XYZ Laboratory would represent a positive feature for the laboratory as it would increase its trustworthiness in relation to its customers. The results of the evaluation show that implementation of a QMS based on ISO/IEC 17025:2005 is possible. However, the accreditation process is a lengthy and time consuming method. Laboratories normally take around two years to set up the system.

The most time consuming and difficult part is the development of the documentation aspects of the QMS. Quality Plan, Quality Manual, Standard Operating Procedures (SOPs), work instructions, job descriptions and records are some of the documents that need to be created or reviewed. The creation of these documents will require the help of all laboratory personnel and therefore, development of the quality system will have an impact on the work load. Training is another aspect that needs to be considered while implementing the QMS. The laboratory will need to recruit additional personnel in order to maintain the QMS and the guidance of a consultant will be a plus point for the implementation process.

Additional data, collected from MAURITAS, along with some approximate figures were used to estimate the percentage investment required by the important components for the accreditation process as shown in Table 2. Case 1 refers to a laboratory employing local consultancy while case 2 deals with a laboratory using international consultancy. The low end of the Proficiency Testing (PT) costs range has been used for case 1 and the high end for case 2 . It can cost about 1.5 million rupees or more for an average laboratory in Mauritius to be accredited. 
Table 2: Major Components of Accreditation Cost

\begin{tabular}{|lccc|}
\hline Component & Case 1 & Case 2 & A verage \\
\hline Proficiency Testing & $2 \%$ & $2 \%$ & $2 \%$ \\
\hline $\begin{array}{l}\text { Calibration and } \\
\text { Maintenance }\end{array}$ & $2 \%$ & $1 \%$ & $1.5 \%$ \\
\hline Surveillance & $5 \%$ & $2 \%$ & $3.5 \%$ \\
\hline $\begin{array}{l}\text { Application, Assessment } \\
\text { and Accreditation }\end{array}$ & $18 \%$ & $7 \%$ & $12.5 \%$ \\
\hline Consultancy & $72 \%$ & $88 \%$ & $80 \%$ \\
\hline
\end{tabular}

\subsection{Recommendation for Implementation of ISO 17025:2005 at XYZ Laboratory.}

A structured approach should be adopted whilst implementing ISO/IEC 17025:2005... XYZ laboratory forms part of a company that is actually implementing the MS ISO 9001standard. Therefore the company is already familiar with systems implementation. The difference lies at the scope of tests that need to be defined for ISO 17025 implementation. Selected tests will be based on factors which directly affect customer needs for quality of products and statutory and regulatory norms for production. The main steps for the implementation of the standards are as shown in Table 3. 
Table 3: Steps for Implementing ISO 17025 in Laboratories.

What should an organization do to implement ISO 17025? There are some basic steps that each organization should go through regardless of the maturity of the QMS

1. Appointment of a Quality manager and Technical management of laboratory by Top management

2. Review actual Management Systems in place.

3. Devise a plan for the implementation of the standard

4. Work out a policy statement

5. Determine Scope of tests to be accredited for

6. Determine their tests methods and validation parameters
7. Train personnel to estimate uncertainty measurement of test methods

8. Engage in an interlaboratory proficiency testing scheme if available.

9. Calibration of equipment should be traceable to appropriate measurement standards

10. Recommend for appropriate environmental conditions

11. Provide for right training

12. Appropriate mechanisms should be in place for quality control.

\subsubsection{Implementation Guidelines}

\section{- Starting Point: Understanding ISO/IEC 17025:2005}

Top management and personnel of XYZ Laboratory should be committed to the implementation quality in a testing laboratory. One important step when developing or planning the implementation of an ISO/IEC 17025 quality system is the appointment of the quality manager and of the technical management of the laboratory by top management. Where needed, adequate training should be provided to relevant staff. 


\section{Evaluation and Comparison of Actual System}

The evaluation and comparison of the quality system of XYZ laboratory has already been carried out and is given in section 5.1. Similar comparisons must be made to confirm the results.

\section{Planning}

XYZ Laboratory should make use of the gap analysis to devise a plan for the implementation of the standard. The plan should address the preparation of documents related to procedures and work instructions and how the work will be distributed among the staff. The quality manager should coordinate all the work and find out what resources will be needed to implement the system.

Other aspects that should be mentioned in the plan are:

1) The time expected to complete the implementation of the system.

2) The accreditation body to be chosen.

3) Training sessions, seminars or workshops for laboratory personnel.

Implementation of the standard involves a lot of work and the role of the quality manager is to synchronize the laboratory work and the implementation programme. Laboratory personnel should develop a new time table for their work in order to accommodate slots for the implementation program as they will be the ones developing the new procedures. The quality manager should guide them and inspect the appropriateness of the written documents.

\section{Quality Management System and Document Control}

\section{Quality Policy Statement}

XYZ Laboratory should develop a quality policy and an example is given in Figure

5. Once the quality policy statement has been signed and read by the personnel, the 
flow of communication needs to be defined. This is normally demonstrated with the help of Organizational charts which show the position held by each staff and the channels of communication for each department and for the organization as a whole. In this chart, generally, the quality manager reports directly to top management. As for the staff, the required level of experience at each post should be described and the limits of responsibility and authority should be well defined.

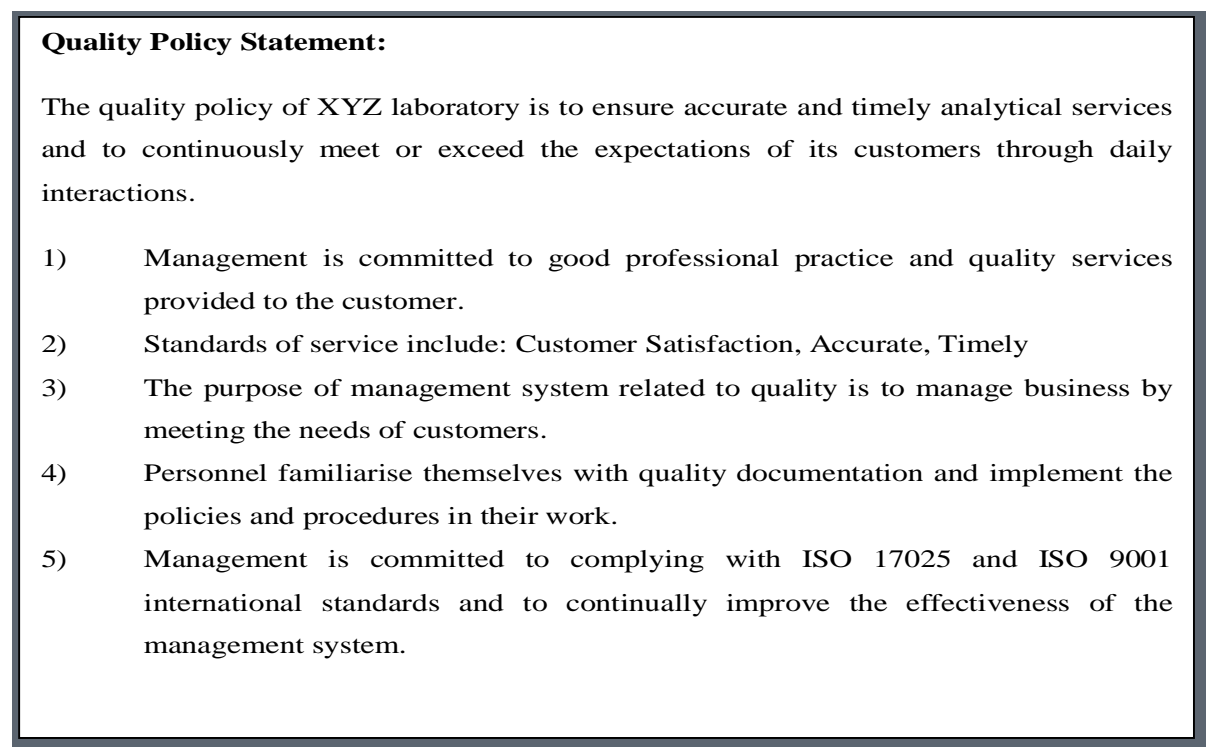

Figure 5: Quality Policy statement developed for XYZ Laboratory

Other important documents of importance for the implementation of the standards would be the job descriptions of key staff, as they define the responsibilities and functions of each post. Appointed staff would be authorized to release work; sign reports should be well designated as they will be held responsible for the proper maintenance of laboratory records. All laboratory records should be properly controlled and maintained by a proper audit mechanism in place in the implementation process. When laboratory personnel are familiar with the document control system, they will know what should be done when they are creating new procedures or records. A procedure should be held for the control of non-conforming tests and for equipment calibration. The documentation systems should also protect the records and allow easy retrievability. Finally all procedures and records created 
should abide by an existing document control procedure. It is to be highlighted that controlled documents are audited in a Quality Management System.

\section{Scope of Tests General}

Defining the scope of accreditation represents the next step. The scope of accreditation contains information about the testing field (e.g. chemical), the measurement principle, the products to be tested and the procedures used for the tests (ILAC 2002). Some parameters used to indentify tests are:

- The quantities to be measured

- Measurement range

- Associated uncertainties

The description of the scope should be precise and should contain either the method used or the equipment operated and a description of the measurement principle. Though the possibility of introducing methods is accepted, new principles of measurement should not be introduced in an accredited scope, without assessment from an accreditation body (ILAC 2002).

Table 4: Scope for Different Testing Fields - Source (SGS Mauritius)

\begin{tabular}{|c|c|c|}
\hline \multicolumn{3}{|c|}{ Field of Testing: Chemical and Biological Testing } \\
\hline Product & Parameter & Method \\
\hline \multirow{2}{*}{ Foods } & Salt & OMA - AOAC $18 \mathrm{e} 937.09$ \\
\hline & Total Solids/Moisture & OMA - AOAC $18 \mathrm{e} 952.08$ \\
\hline \multicolumn{3}{|c|}{ Field of Testing: Environmental Testing } \\
\hline \multirow{2}{*}{$\begin{array}{l}\text { Water and } \\
\text { Wastewater }\end{array}$} & Settleable solids & APHA 21e 2540F \\
\hline & $\begin{array}{l}\text { Total, Fixed and Volatile } \\
\text { Solids }\end{array}$ & APHA 21e 2540G \\
\hline \multicolumn{3}{|c|}{ Field of Testing: Mechanical Testing } \\
\hline \multirow{2}{*}{$\begin{array}{ll}\text { Textiles and } \\
\text { Garments }\end{array}$} & Fabric Weight & BS EN 12127: 1998 \\
\hline & Yarn Counts & ASTM D1907: 1997/2007 \\
\hline
\end{tabular}


XYZ Laboratory should prepare a formal and precise statement of the tests it wants to be accredited for. As XYZ Laboratory is a water and wastewater testing laboratory, it will generally include APHA methods in its scope. An example of the scope of tests identified for the laboratory is given in Table 5 below.

Table 5: Scope of Tests identified for XYZ (For Accreditation purposes)

\begin{tabular}{|c|c|c|}
\hline PRODUCT & TEST PARAMETERS & TEST METHODS \\
\hline \multirow{19}{*}{$\begin{array}{l}\text { Water and } \\
\text { Wastewater }\end{array}$} & Physical Testing & \\
\hline & Appearance & APHA 21e 2110 \\
\hline & Conductivity & APHA 21e 2510B \\
\hline & $\mathrm{pH}$ Value & APHA 21e $4500-\mathrm{H} B$ \\
\hline & Sludge Volume index & APHA 21e $2710 \mathrm{D}$ \\
\hline & Settleable Solids & APHA 21e $2540 \mathrm{~F}$ \\
\hline & Total Solids at $103-105^{\circ} \mathrm{C}$ & APHA 21e 2540 B \\
\hline & Total Dissolved Solids at $180^{\circ} \mathrm{C}$ & APHA 21e $2540 \mathrm{C}$ \\
\hline & Fixed and Volatile Solids at $550^{\circ} \mathrm{C}$ & APHA 21e $2540 \mathrm{E}$ \\
\hline & Temperature & Thermometry \\
\hline & Chemical Testing & \\
\hline & Alkalinity as $\mathrm{CaCO} 3$ & APHA 21e 2320 B \\
\hline & Chloride & APHA $21 \mathrm{e} 4500 \mathrm{Cl}-\mathrm{B}$ \\
\hline & Total Hardness as $\mathrm{CaCO} 3$ & APHA 21e $2340 \mathrm{C}$ \\
\hline & Nitrogen, Ammonia & APHA 21e $4500 \mathrm{NH}_{3}-\mathrm{B}$ \\
\hline & Nitrogen, Nitrite & APHA $21 \mathrm{e} 4500 \mathrm{NO}_{2}-\mathrm{B}$ \\
\hline & Aluminium & APHA 21e 3111D \\
\hline & Barium & APHA 21e 3111D \\
\hline & Total Chromium & APHA 21e 3111D \\
\hline
\end{tabular}

\section{Test Methods and Method of Validation}

Clause 5.4.1 of ISO/IEC 17025:2005 standard requires that a laboratory makes use of appropriate methods. These methods should suit the needs of clients and, if possible, 
the methods should be standard methods. This is not always the case and when non standard methods are used, they should be fully validated and documented.

\section{What is Method Validation?}

Method validation is the process of describing an analytical requirement and evaluating the method's performance capabilities. Method validation should be carried out with equipment that has been properly calibrated (EURACHEM The Fitness for Purpose of Analytical Methods 1998.)

\section{Parameters for Method Validation}

The parameters for method validation have been defined in different working groups of national and international committees and are described in the literature. Unfortunately, some of the definitions differ between different organizations. An attempt for harmonization was made for pharmaceutical applications through ICH where representatives from the industry and regulatory agencies form the US, Europe and Japan defined the parameters for analytical methods validations. The parameters as defined by $\mathrm{ICH}$ and by other organizations and authors, are summarized in Table 6.

\section{Table 6: Possible Analytical parameters for method validation}

\begin{tabular}{|l|l|}
\hline Specificity & Bias \\
\hline Selectivity & Linearity \\
\hline Precision & Range \\
\hline repeatability & Limit of detection \\
\hline $\begin{array}{l}\text { Intermediate } \\
\text { precision }\end{array}$ & Limit of quantitation \\
\hline reproducibility & Robustness \\
\hline Accuracy & Ruggedness \\
\hline Trueness & \\
\hline
\end{tabular}

Source: EURACHEM Guide (1998) "The Fitness for Purpose of Analytical Methods. 


\section{Extent of Method validation}

Validation can be stopped when the laboratory concludes, from accumulated results, that the method is suitable for the stated purpose. The extent depends on the type of method. If it is a documented in-house method, then, validation will be complex as most of the performance parameters should be assessed. In the case of documented in-house methods based on standard specifications, validation will be less complicated. For standard methods, some validation for the accuracy and precision are required because there is no guarantee that the skills of operators or performance of instruments are the same as those used to generate the standard validation data (Rowley 2005). It is to be highlighted that validation is needed when laboratory uses non standard methods, laboratory designed/developed methods, standard methods used outside their intended scope and amplifications and modifications of standard methods. On the other hand when a laboratory uses a standard method, there is a need for verification (which is a small scale validation). Verification includes at least repeatability, reproducibility, and trueness (expressed as bias or recovery).

XYZ laboratory makes use of both standard methods and documented in-house methods based on standard methods. These types of tests methods require validation and XYZ laboratory should determine the following parameters before validation. Parameters like bias, selectivity and limit of detection are already given in the standard test method.

\section{Equipment Calibration and Identification}

XYZ laboratory already has the appropriate equipment records. The evaluation of the actual QMS showed that procedures for equipment are missing. Table 7 provides are equipment procedures that need to be developed. Equipment calibration was also restricted to balances, electronic meters and other complex equipment. XYZ laboratory is therefore recommended to extend its calibration program to the list provided in Table 8 . 


\begin{tabular}{|ll|}
\hline $\begin{array}{l}\text { Table } 7 \text { : List of appropriate } \\
\text { Procedures for Equipment }\end{array}$ & $\begin{array}{l}\text { Table 8 : Additional list of } \\
\text { Equipment to be calibrated }\end{array}$ \\
Calibration and Identification & \\
\hline - Safe Handling Procedures & - Pipettes \\
- Transport Procedures & - Volumetric Flasks \\
- Out of service Procedures & - Thermometers \\
- Return to Service & - Timing Devices \\
Procedures & Intermediate Calibration \\
Procedures & - Furnaces \\
\hline
\end{tabular}

Calibrated Equipment should then properly identified by providing information such as equipment identification number, the equipment model, the calibration frequency, the last date it was calibrated, the due date for the next calibration and the initials of the person having carried out the calibration process. In order to ease the calibration process, computer software can be used to store equipment and calibration records.

\section{Uncertainty of Measurement}

Estimation of uncertainty of measurement is a requirement of the ISO/IEC 17025:2005 standard. The uncertainty is defined as a parameter, associated to the measurement value, which characterises the dispersion of the values that could be attributed to the measurand (ILAC Introducing the Concept of Uncertainty of Measurement in Testing in Association with the Application of the Standard ISO/IEC 17025 2002). There are different factors which may contribute to the overall uncertainty of measurement as shown in Figure 5. 


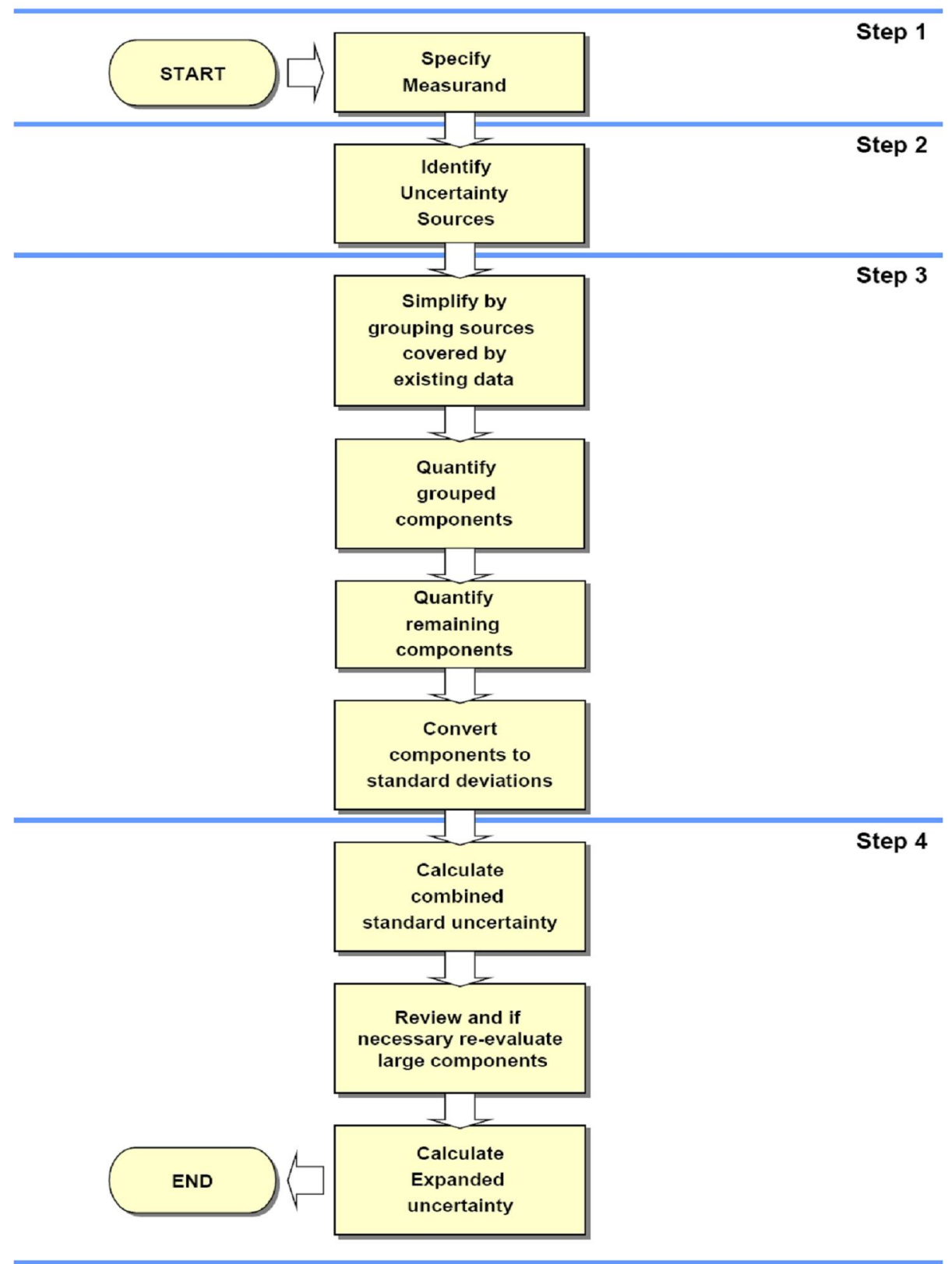

Figure 5: Flowchart Showing Various Steps in Estimating Uncertainty of Measurement

Source: EURACHEM/CITAC Guide CG4 (2000) 
XYZ laboratory does not possess the procedures for the determination of uncertainty of measurement. Therefore, the laboratory personnel need to be trained to estimate the uncertainty of methods. Areas requiring uncertainty estimation are given in Table 9.

\begin{tabular}{|l|l|}
\hline \multicolumn{2}{|c|}{ Table 9: Uncertainty Components } \\
\hline 1. Sampling & 4. Equipment \\
2. Sample Preparation & 5. Calibration Standards \\
3. Analyst Effects & $\begin{array}{l}\text { 6. Reference materials } \\
\text { Cont... }\end{array}$ \\
\hline
\end{tabular}

The following can be used as a guide in the estimation of uncertainty of measurement (Eurachem 2000). It was observed that for some laboratories visited it was a most difficult step to master for the process of accreditation. This task needs to be delegated to adequately trained personnel.

To estimate the uncertainty, a four step process is used. The steps described below are only indicative and it is not the full process of estimation of uncertainty for $\mathrm{pH}$

1) Specify the measurand.

What is being measured should be stated along with the other input quantities on which it depends.

2) Identify the uncertainty sources.

Sources of uncertainties should be listed.

3) Quantify uncertainty components.

Each potential source of uncertainty should be given a value.

4) Calculate the combined uncertainty.

The combination of the uncertainty values, using appropriate rules and expressed as standard deviations, gives a combined standard uncertainty. 


\section{Measurement Traceability}

The international definition for traceability mentions that it is the "Property of the result of a measurement or the value of a standard whereby it can be related to stated references, usually national or international standards, through an unbroken chain of comparisons all having stated uncertainties" (Eurachem 2003).

Calibration, using an appropriate measurement standard, is important in establishing traceability. Laboratories should send their standards for calibration in ISO 17025 accredited laboratories. Calibration standards, generally used, consist of certified reference materials (CRMs), pure materials and reference data. A CRM is a sample for which the values are known and recognised on an international level. Laboratories generally use CRMs for periodic performance checks of their methods. Whereas calibration reference standards are used for calibration of equipment and provide a guarantee of accuracy.

For testing laboratories, in-house calibrations will require the use of references which have a calibration certificate, delivered by an accredited calibration laboratory. For example, a reference thermometer, calibrated by an accredited laboratory, can be used to calibrate other thermometers (Rowley 2005). In-house calibrations are usually carried out for thermometers, spectrometers, $\mathrm{pH}$ meters and conductivity meters. Equipment, requiring expensive references for calibration, can undergo external calibration in accredited laboratories. One important determining factor of traceability is calibration with appropriate measurement standards. It has been noticed that XYZ laboratory does not apply the correct calibration frequency. Table 10 recommends the calibration frequency to be applied to equipment. 
Table 10: Calibration Frequency

\begin{tabular}{|l|c|}
\hline \multicolumn{1}{|c|}{ Equipment } & $\begin{array}{c}\text { Recommended Calibration } \\
\text { Frequency }\end{array}$ \\
\hline - Reference thermometers & $\bullet$ Annually \\
- Balances & $\bullet$ Annually \\
- Calibration Weights & $\bullet \quad$ Every five years \\
$\bullet$ Volumetric glassware & $\bullet$ Annually \\
\hline
\end{tabular}

Source: Eurachem Accreditation in Microbiological Laboratories

\section{Recommendations for Accommodation and Environmental Conditions}

XYZ Laboratory should review its premises as there is a lack of space. The laboratory is, also, recommended to control the environmental parameters. A summary of recommendations is given below.

\begin{tabular}{|c|c|}
\hline $\begin{array}{l}\text { Table } 11 \text { : Recommendation for } \\
\text { Accommodation }\end{array}$ & $\begin{array}{l}\text { Table } 12 \text { : Recommendation for } \\
\text { Environment }\end{array}$ \\
\hline $\begin{array}{l}\text { - Storage space for test items } \\
\text { should be reviewed } \\
\text { - Space for documentation and } \\
\text { records should be considered } \\
\text { - Access to the laboratory } \\
\text { should be restricted to } \\
\text { personnel }\end{array}$ & $\begin{array}{l}\text { - } \begin{array}{l}\text { Temperature and humidity } \\
\text { should be controlled and } \\
\text { recorded }\end{array} \\
\text { - Working areas should be } \\
\text { cleaned regularly } \\
\text { - Lighting should be } \\
\text { appropriate }\end{array}$ \\
\hline
\end{tabular}

\section{Staff Training}

The evaluation of the QMS showed that staff training was insufficient. Regarding the estimation of uncertainty, personnel did not receive any training related to this topic. Newly recruited personnel learn and try test methods on their own. Therefore, XYZ laboratory needs to train its employees on estimation of uncertainty of 
measurement. The laboratory should, also, ensure that new recruits work under the supervision of experienced staff.

\section{Quality Control and Auditing}

The assessment of the actual QMS of XYZ laboratory indicated that the only method of quality control being applied was duplication of tests. As quality control is inadequate, XYZ laboratory is recommended to participate in Proficiency Testing (PT) schemes. The MSB has recently launched its PT program for water testing laboratories and XYZ laboratory should participate in it. The laboratory can also use its records to generate control charts and detect non-conforming work.

Auditing is being carried out on the requirements of the ISO 9001 standard by XYZ laboratory. In order to determine their progress rate in the implementation of ISO/IEC 17025:2005, the laboratory should plan the audit of the technical requirements of the standard. XYZ laboratory is recommended to employ auditors having background knowledge of technical requirements.

Agreed time scale for the implementation of corrective actions should be respected. XYZ laboratory should also find more opportunities for preventive actions in order to prevent deterioration of quality.

\section{Proficiency Testing (PT) Schemes}

Proficiency testing exercises, by exchanging samples and comparing results among laboratories, demonstrates effectiveness of internal reproducibility and accuracy of results. PT schemes are very effective for quality control and can be an informal process between laboratories or organised by a third party bodies. The data generated can be used to initiate remedial actions in laboratories not reaching the required performance level. 
Therefore, Sampling is an important step in the measurement process and is a requirement -clause 5.7 of the standard. A sampling plan is often used as it contains instructions on the collection and handling of a test sample and these help in the determination of uncertainty in the final results. Therefore, proper sampling and handling are essential for the generation of valid results.

\section{Accommodation and Environmental Conditions}

Clause 5.3 of ISO/IEC 17025:2005 states that the facilities available in a laboratory should facilitate the correct performance of tests and that the environmental conditions should be monitored, controlled and recorded to minimise influence on the results.

Some rules for a chemical testing laboratory are:

1) Chemical storage, handling and disposal should comply with the health and safety legislation.

2) Segregated areas should be provided where the possibility of cross contamination exists.

3) The temperature should be monitored, controlled and recorded as some test methods are expected to work within a specific range of temperatures.

4) Good housekeeping and tidiness should be imposed.

5) A system for reporting and recording spillages should be available.

6) Access to the laboratory should be restricted to personnel and visitors should be accompanied by staff.

\section{CONCLUSIONS}

ACCREDITATION by definition is the procedure, based on internationally agreed criteria, by which an authoritative body provides a formal recognition that a body or a person is in a position to carry out specific tasks with impartiality and competence. Accreditation of a laboratory provides a formal recognition that the laboratory is competent to carry out specific tests and demonstrates its impartiality. ISO/IEC 17025, General requirements for the competence of testing and calibration 
laboratories, is the main standard used by testing and calibration laboratories. Originally known as ISO/IEC Guide 25, ISO/IEC 17025 was initially issued by the ISO in 1999. It has many commonalities with ISO 15189:2007 Medical Laboratories- Particular requirements for quality and competence specifies the quality management system requirements particular to medical laboratories. The standard was developed by the International Organisation for Standardisation' Technical Committee 212 (ISO/TC 212). Its development was strongly influenced by the EC4 Essential Criteria for Quality Systems in Medical Laboratories. While the standard is based on ISO/IEC 17025 and ISO 9001, it is a unique document that takes into consideration the specific requirements of the medical environment and the importance of the medical laboratory to patient care

Throughout the report, the benefits, associated to the implementation of a QMS and accreditation to 17025 , have been demonstrated. With customers having understood the concept of having better quality than quantity, accreditation is becoming a must for companies eager to satisfy their clients.

The evaluation results show that XYZ Laboratory will need to develop a QMS based on the ISO/IEC 17025:2005 standard and implement it. Some of the clauses of the standard are already being operated in the laboratory but they require modifications to comply fully with the requirements. The summary of the evaluation of the actual system can be used as a starting point to fill the gap between actual conditions and recommended requirements.

With the implementation of ISO/IEC 17025:2005, the laboratory, the personnel and the clients enjoy various benefits. Better traceability, involvement of personnel in decision making processes, acknowledgement of testing competence, benchmark for performance, marketing advantage, international recognition, risk minimisation, customer confidence and cost reduction are the main advantages which are achieved.

The feasibility study of accreditation has shown that the process is a lengthy and demanding endeavour. Laboratory accreditation is achieved at a certain cost and 
financial support from top management is vital to the success of the implementation process. Training, equipment calibration and maintenance, consultancy, application and assessment by an accreditation body, IQC, PT, preventive and corrective actions are the processes that will require investment from top management.

The guidelines, developed for a testing laboratory, for the implementation of ISO/IEC 17025:2005, also, show that there are various requirements to be fulfilled before a laboratory is ready for assessment and accreditation.

Laboratory accreditation is a challenging process and the commitment of top management and staff involvement will determine the success of the implementation of a QMS based on ISO/IEC 17025:2005

\section{REFERENCES}

1. CITAC/EURACHEM, 2002. guide to quality in analytical chemistry: an Aid to Accreditation Retrieved $18^{\text {th }}$ November 2008 from http://www.eurachem.org/guides/CITAC\%20EURACHEM\%20 GUIDE.pdf

2. EURACHEM, 1998. The Fitness for Purpose of Analytical Methods: A Laboratory Guide to Method Validation and Related Topics. Retrieved $1^{\text {8th }}$ November 2008 from http://www.eurachem.org/guides/valid.pdf

3. EURACHEM/CITAC, 2000. Quantifying uncertainty in Analytical Measurement. Retrieved $18^{\text {th }}$ November 2008 from: http://www.eurachem.org/guides/UfS_2007.pdf.

4. EURACHEM/CITAC, 2003. Traceability in Chemical Measurement: A Guide to Achieving Comparable Results in Chemical Measurement. Retrieved $18^{\text {th }}$ November 2008 from: http://www.eurachem.org/guides/EC Trace 2003.pdf. 
5. GOLZE M., 2003. Quality Management in Analytical Laboratories According to ISO/IEC 17025. Retrieved $17^{\text {th }}$ October 2008 from: http://www.ecasia03.bam.de/pdf/golze iso 17025.pdf.

6. ILAC, 2001. Laboratory Accreditation or ISO 9001 Certification? Retrieved $13^{\text {th }}$ December 2008 from: http://www.ilac.org/documents/Bro_english/Laboratory_accred_orcert.pdf.

7. ILAC, 2002. Introducing the Concept of Uncertainty of Measurement in Testing in Association with the Application of the Standard ISO/IEC 17025:2005. Retrieved $13^{\text {th }}$ December 2008 from:

http://www.ilac.org/documents/ILAC_G172002_intro_the_concept_of_uncert_meas_with_17025.pdf.

8. ILAC, 2004. Use of Proficiency Testing as a Tool for Accreditation in Testing Retrieved $13^{\text {th }}$ December 2008 from:

http://www.ilac.org/documents/ILAC_G22 2004 use of proficiency testi $\underline{\text { ng as a tool for accreditation in testing.pdf. }}$

9. ILAC, 2007. Guidelines for the Determination of Calibration Intervals of Measuring Instruments. Retrieved $13^{\text {th }}$ December 2008 from: http://www.ilac.org/documents/ILAC_G24_2007.pdf.

10. ILAC, 2008. How Does Using an Accredited Laboratory Benefit Government and Regulators. Retrieved $13^{\text {th }}$ December 2008 from:

http://www.ilac.org/documents/Bro english/How does using benefit.pdf.

11. MAURITAS, 2008. The Mauritian Accreditation Service Retrieved $15^{\text {th }}$ August 2008 from:

http://www.gov.mu/portal/site/industrysite/menuitem.02db28c6296cfd4db33 $\underline{47524 \mathrm{e} 2 \mathrm{~b} 521 \mathrm{ca} / .}$.

12. MS ISO 17025:2005. General Requirements for the Competence of Testing and Calibration Laboratories. ISO, Geneva (2005) 
13. RATLIFF T.A., 2003. The Laboratory Quality Assurance System: A Manual of Quality Procedures and Forms. $3^{\text {rd }}$ Ed. New Jersey: John Wiley \& Sons.

14. ROWLEY A.G., 2005. Some Guidance Notes for Method Validation, Statistics and Quality Control for Analytical Chemistry. Alan Rowley Associates.

15. Singapore Accreditation Council, 2008. Information on Accreditation. Retrieved $18^{\text {th }}$ September 2008 from: http://www.sac-accreditation.org.sg/.

16. PENDRILL L. (2008) New developments in measurement uncertainty in chemical analysis. Accreditation and Quality Assurance: Journal for Quality, Comparability and Reliability in Chemical Measurement, Vol. 13, No. 11. (1 November), pp. 671-674. 